\title{
Artesunate enhances TRAIL-induced apoptosis in human cervical carcinoma cells through inhibition of the NF-kB and PI3K/Akt signaling pathways
}

\author{
ORANUCH THANAKETPAISARN ${ }^{1}$, PORNTHIP WAIWUT ${ }^{2}$, HIROAKI SAKURAI $^{2}$ and IKUO SAIKI $^{2}$ \\ ${ }^{1}$ Faculty of Pharmaceutical Sciences, Ubonratchathani University, Ubonratchathani 34190, Thailand; ${ }^{2}$ Division \\ of Pathogenic Biochemistry, Institute of Natural Medicine, University of Toyama, Toyama 930-0194, Japan
}

Received December 10, 2010; Accepted February 21, 2011

DOI: 10.3892/ijo.2011.1017

\begin{abstract}
Tumor necrosis factor-related apoptosis-inducing ligand (TRAIL) selectively induces apoptosis and kills cancer cells with little or no adverse effects on normal cells. TRAIL is relatively safe for clinical applications. However, TRAIL resistance is widely found in cancer cells leading to limitations in utilizing TRAIL as a therapeutic agent for cancer treatment. Recently, artesunate, an effective and safe anti-malarial drug, was also described as a promising candidate for cancer therapy. It would be of importance to determine whether combination treatment of TRAIL together with artesunate could overcome drug-resistance of tumors. Here, we demonstrate the first evidence that artesunate effectively enhances TRAIL-mediated cytotoxicity by suppressing pro-survival proteins, such as survivin, XIAP and Bcl-XL. Upon treatment with artesunate, the levels of survival proteins were strongly suppressed in HeLa cells. The down-regulation of these survival proteins could be regulated by repressing activation of NF- $\mathrm{kB}$ and Akt. Artesunate also inhibited TRAIL-induced transcriptional activity of NF- $\mathrm{KB}$. In addition, this substance significantly enhanced both extrinsic and intrinsic apoptosis, which were induced by TRAIL. Taken together, the results of the present study suggest that artesunate exhibits an ability to overcome TRAIL resistance and combination treatment of TRAIL
\end{abstract}

Correspondence to: Professor Ikuo Saiki, Division of Pathogenic Biochemistry, Department of Bioscience, Institute of Natural Medicine, University of Toyama, 2630 Sugitani, Toyama 930-0194, Japan

E-mail: byosei@inm.u-toyama.ac.jp

Abbreviations: TNF, tumor necrosis factor; TRAIL, related apoptosis inducing ligand; $\mathrm{NF}-\kappa \mathrm{B}$, nuclear factor kappa-light-chain-enhancer of activated B cells; PI3K, phosphoinositide 3-kinase; Akt, serine/ threonine protein kinase; MAPK, mitogen-activated protein kinase; DISC, death-inducing signaling complex; cFLIP, cellular FLICElike inhibitory protein; Bid, $\mathrm{BH} 3$ interacting domain death agonist; Bcl-xL, B-cell lymphoma-extra large; XIAP, X-linked inhibitor of apoptosis protein

Key words: artesunate, TRAIL, NF-кB, PI3K/Akt, survivin, apoptosis together with artesunate may be an effective strategy for cancer therapy.

\section{Introduction}

The tumor necrosis factor (TNF)-related apoptosis inducing ligand (TRAIL), a member of the tumor necrosis factor superfamily, has attracted great interest due to its specific anti-tumor potential without toxic side effects. It selectively induces proteins that initiates apoptosis in a variety of neoplastic cells while displaying minimal or absent cytotoxicity to most normal cells $(1,2)$. Studies in non-human primates such as chimpanzees and cynomolgus monkeys show no toxicity upon intravenous infusion, even at high doses (3). TRAIL has become a recognized target for cancer therapy. TRAIL binds to TRAIL-R1 or TRAIL-R2, two death domain-containing receptors, also called DR4 and DR5, to trigger apoptosis $(4,5)$. It has been also described that TRAIL can induce survival signals in some cell types especially by inducing the prosurvival and proinflammatory transcription factor $\mathrm{NF}-\kappa \mathrm{B}$, phosphoinositide 3-kinase/Akt (PI3K/Akt) and mitogenactivated protein kinase (MAPK) pathways via JNK activation (6). Unfortunately, a considerable range of cancer cells, especially some highly malignant tumor, is resistant to induction of apoptosis by TRAIL (5). Resistance to TRAIL seems to be mediated through multiple mechanisms in the signaling pathways of TRAIL-induced apoptosis, including mutations in the death receptors, defects in the molecules involved in formation of the death-inducing signaling complex (DISC), dysregulation of DISC activation by TRAIL receptor antagonists, overexpression of cellular FLICE-like inhibitory protein (cFLIP) and enhancement in expression of caspase inhibitors and other cell survival proteins (4-7). The emergence of resistance to TRAIL is a major problem limiting its utility as a therapeutic agent. Combination of TRAIL with chemotherapy or radiotherapy significantly enhances cytotoxicity to tumors and overcome this problem, and unfortunately, they come with severe toxic side effects inducing cell death processes in both malignant and non-malignant cells (7-9). Therefore, there is a necessity for agents that are safe and efficacious in potentiating the effects of TRAIL leading to overcome such resistance and successful use of TRAIL for cancer therapy. The 
search for novel antitumor agents that circumvent several limitations has increased its attention toward natural sources, in particular plant compounds. Artesunate is one of semisynthetic derivatives of artemisinin isolated from decoctions of traditional Chinese medicine Artemisia annua L (qinghao, sweet wormwood) (10). During recent years artemisinin and its derivatives have emerged as the most effective and safe drugs for the treatment of severe and chloroquine-resistant malaria (11). There is increasing evidence to support the notion that artesunate might be a highly interesting compound to be used in cancer. First encouraging investigation in clinical treatment of uveal melanoma suggested further clinical trials with artesunate for cancer treatment in the near future (12). Artesunate triggers apoptotic cell death in various tumor cells in both a p53-dependent and -independent manner $(13,14)$. Artesunate has been shown to inhibit the growth of Kaposi's sarcoma cells, a highly angiogenic multifocal tumor, and that activity of cell growth inhibition correlated with the induction of apoptosis (15). So far, the effects of artesunate in enhancing TRAIL-induced apoptosis in tumor cells have not been elucidated. It would be interesting to know, whether combination of artesunate and TRAIL could overcome drug-resistance of tumors. This combination treatment might be an alternative promising strategy for cancer therapy. In the present study, we investigated the efficacy of artesunate to sensitize human cervical cancer cells to TRAIL, and further investigated its intracellular signaling mechanism in sensitizing TRAILinduced apoptosis by artesunate.

\section{Materials and methods}

Chemicals and reagents. Artesunate (Guilin Pharmaceutical Corp. Ltd., China) was dissolved in dimethyl sulfoxide (DMSO) and kept as a stock solution at $-20^{\circ} \mathrm{C}$. The final concentration of DMSO was kept below $0.1 \%$ throughout the study. Recombinant human TRAIL and recombinant human tumor necrosis factor (TNF- $\alpha$ ) were purchased from Peprotech (London, UK). Primary antibodies specific to caspase-3, caspase-7, caspase-8, poly (ADP-ribose) polymerase (PARP), BH3 interacting domain death agonist (Bid), B-cell lymphoma-extra large (Bcl-xL), $\mathrm{X}$-linked inhibitor of apoptosis protein (XIAP), survivin and phosphorylated form of Akt (Ser473), extracellular-signalregulated kinase (ERK) (Thr202/Tyr204), p38 (Thr180/Tyr182), c-Jun NH2-terminal kinase (JNK) (Thr183/Tyr185), p65 (Ser536) were obtained from Cell Signaling Technology (Beverly, MA, USA). Primary antibodies specific to actin, caspase-9, Akt, ERK, p38, JNK, and p65 were obtained from Santa Cruz Biotechnologies (Santa Cruz, CA, USA).

Cell culture and treatment. HeLa human cervical cancer cells (ATCC, Rockville, MD, USA) and stably transfected with $\mathrm{NF}-\kappa \mathrm{B}$-luciferase reporter plasmid were cultured in Dulbecco's modified Eagle's medium (DMEM) supplemented 10\% heatinactivated fetal calf serum, $2 \mathrm{mM}$ L-glutamine, 100 units $/ \mathrm{ml}$ of penicillin, and $100 \mu \mathrm{g} / \mathrm{ml}$ of streptomycin. Cultures were maintained at $37^{\circ} \mathrm{C}$ in a humidified atmosphere of $5 \% \mathrm{CO}_{2} /$ $95 \%$ air.

Cell viability assay. Viability of cells after treatment was determined by WST-1 Cell Counting kit (Wako Pure Chemical
Industries, Osaka, Japan) as previously described (16). Cells were seeded into a 96-well plate $\left(6 \times 10^{3} / 80 \mu \mathrm{l} /\right.$ well $)$. After $24 \mathrm{~h}$ of incubation, medium containing artesunate $(10 \mu \mathrm{l})$ was added to the wells and cells were incubated for $30 \mathrm{~min}$. TRAIL in medium $(10 \mu \mathrm{l})$ was added to each well, and further incubated for $24 \mathrm{~h}$. WST-1 solution $(10 \mu \mathrm{l})$ was added to each well and incubated at $37^{\circ} \mathrm{C}$ for $1 \mathrm{~h}$. The absorbance at $450 \mathrm{~nm}$ was measured using a microplate reader. Cell viability was determined from the absorbance of soluble formazan dye generated by living cells.

Immunoblot analysis. Immunoblot analysis was performed as previously described (17). Cell was seeded and incubated overnight in a $60 \mathrm{~mm}$ culture dish $\left(1 \times 10^{6} / 4 \mathrm{ml} /\right.$ well $)$. After treatment, whole cell lysates from HeLa cells were prepared with lysis buffer (25 mM HEPES pH 7.7, $0.3 \mathrm{M} \mathrm{NaCl}, 1.5 \mathrm{mM}$ $\mathrm{MgCl}$, 0.2 mM EDTA, 0.1\% Triton X-100, 20 mM b-glycerophosphate, $1 \mathrm{mM}$ sodium orthovanadate, $1 \mathrm{mM}$ phenylmethylsulfonyl fluoride (PMSF), $1 \mathrm{mM}$ dithiothreitol (DTT), $10 \mathrm{mg} / \mathrm{ml}$ aprotinin and $10 \mathrm{mg} / \mathrm{ml}$ leupeptin). Cell lysates were subjected to electrophoresis in SDS-PAGE (10\%) and electrophoretically transferred to Immobilon-P nylon membrane (Millipore, Bedford, MA, USA). The membrane was treated with BlockAce (Dainippon Pharmaceutical Co., Ltd., Suita, Osaka, Japan) for at least $2 \mathrm{~h}$, and probed with the indicated primary antibodies overnight, followed by horseradish peroxidase-conjugated secondary antibodies (Dako, Glostrup, Denmark). The results were visualized using ECL reagents (Amersham Bioscience, Piscataway, NJ, USA).

Luciferase reporter assay. $\mathrm{NF}-\mathrm{\kappa B}$ transcriptional activity in the HeLa cells stably transfected with NF- $\kappa \mathrm{B}$-luciferase reporter was determined by luciferase assay. Cells were seeded in 24 -well plate $\left(1 \times 10^{5} / 500 \mu \mathrm{l} /\right.$ well $)$ and left overnight. The cells were pretreated with artesunate $(60 \mu \mathrm{M})$ for $30 \mathrm{~min}$, and further incubated with TRAIL $(200 \mathrm{ng} / \mathrm{ml})$ or TNF- $\alpha(20 \mathrm{ng} / \mathrm{ml})$ for $12 \mathrm{~h}$. Cells were then lysed with $200 \mu \mathrm{l}$ passive lysis buffer (Promega, Madison, WI, USA) and $5 \mu \mathrm{l}$ of cell lysate were mixed with $20 \mu \mathrm{l}$ of luciferase substrate solution (Picagene, Toyo Inc, Tokyo, Japan). Luminescence was determined using a luminometer (Atto, Tokyo, Japan). The luciferase activity was normalized by total protein and then calculated as relative luciferase activity.

Statistical analysis. Data are expressed as the mean \pm SD and analyzed by Student's t-test using SPSS software to determine the significance of differences between groups. A p $<0.05$ was considered to be significant.

\section{Results}

Artesunate enhances TRAIL-induced cell cytotoxicity. Initially, cytotoxicity of artesunate in HeLa cells was determined after $24 \mathrm{~h}$ of treatment with $0-300 \mu \mathrm{M}$ artesunate. The concentration range of 10-60 $\mu \mathrm{M}$ was observed to be non-toxic for HeLa cancer cells, with cell viability being greater than $80 \%$. The cytotoxicity of combination treatment of TRAIL and artesunate was also examined and the results clearly and surprisingly showed the synergist effect of artesunate in TRAIL-induced cell cytotoxicity (Fig. 1A). In addition, the enhancement of 
A

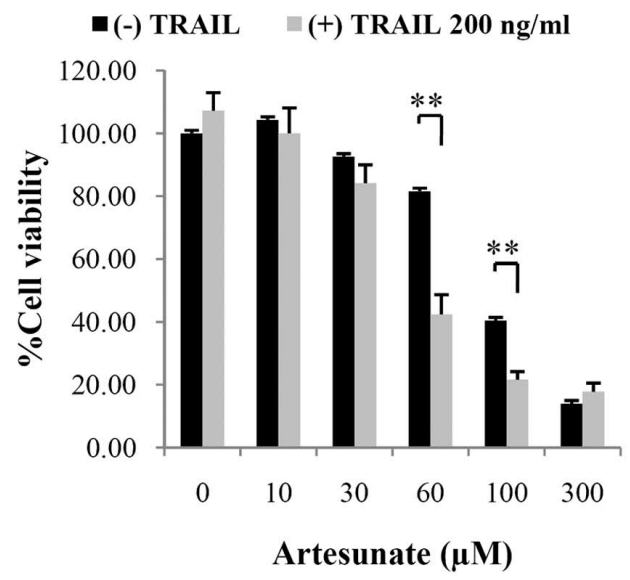

B

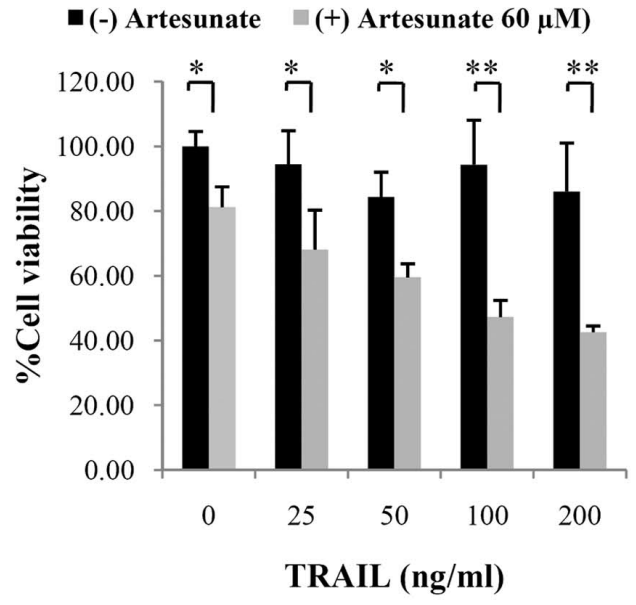

C

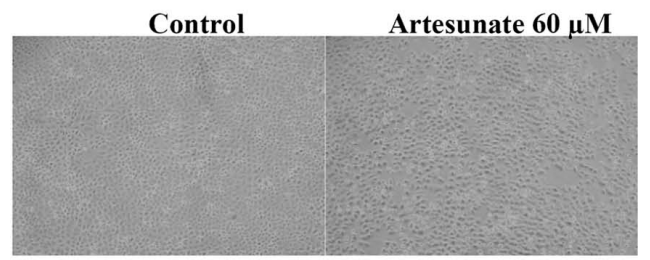

TRAIL $200 \mathrm{ng} / \mathrm{mL}$

Artesunate + TRAII

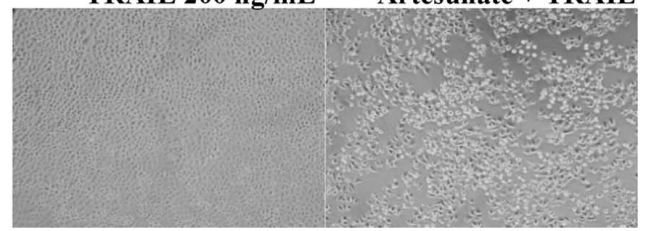

Figure 1. Effect of artesunate on TRAIL-induced cell cytotoxicity. Viability of HeLa cells after treatment was determined by WST-1 assay. (A) Cells were pretreated with artesunate $(60 \mu \mathrm{M})$ or vehicle $(0.1 \%$ DMSO) for $30 \mathrm{~min}$, and further incubated with different concentrations of TRAIL for $24 \mathrm{~h}$. (B) Cells were pretreated with different concentration of artesunate for $30 \mathrm{~min}$, and further incubated in the presence or absence of TRAIL $(200 \mathrm{ng} / \mathrm{ml})$ for $24 \mathrm{~h}$. Data are expressed as the mean \pm SD from at least three independent experiments, and significant differences between groups are shown by ${ }^{*} \mathrm{p}<0.05,{ }^{* *} \mathrm{p}<0.01$. (C) Photographs were taken at original magnification of $\mathrm{x} 50$. Cells were pretreated with artesunate $(60 \mu \mathrm{M})$ for $30 \mathrm{~min}$, followed by incubation in the presence or absence of TRAIL $(200 \mathrm{ng} / \mathrm{ml})$ for $24 \mathrm{~h}$.

TRAIL-induced cell death by artesunate presented in dosedependent manner with the correlation coefficients of 0.972 . The artesunate concentration at $60 \mu \mathrm{M}$ was selected for further studies owing to non-toxic and significantly increased cell death in the combination treatment with TRAIL. The 24-h

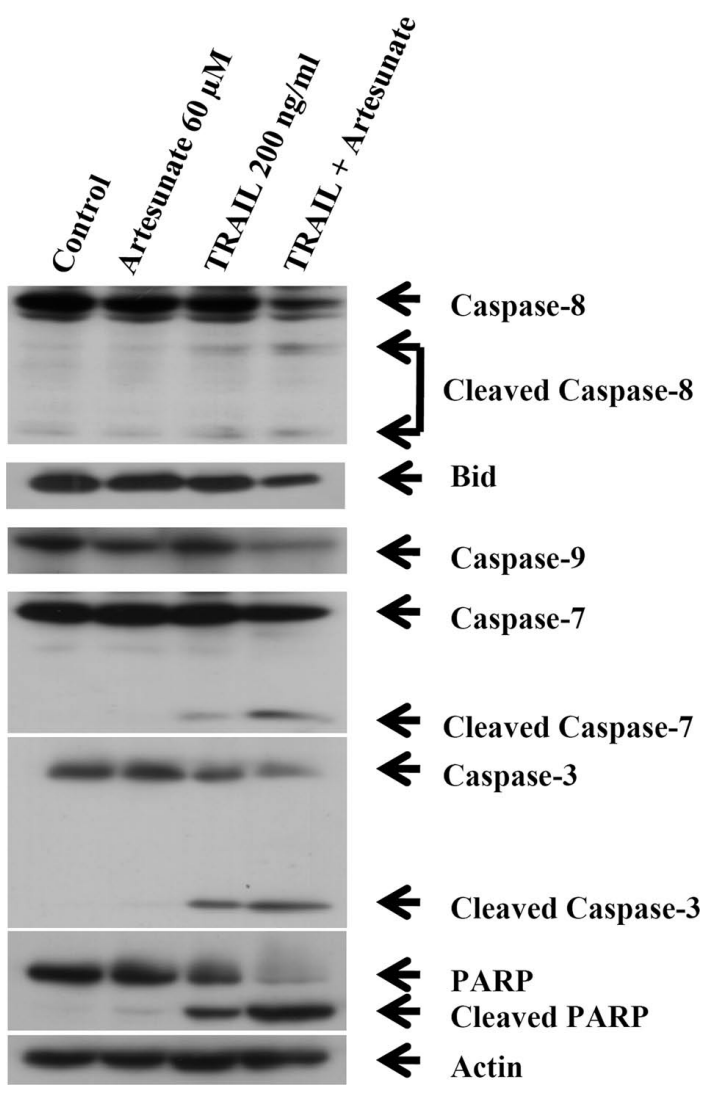

Figure 2. Artesunate enhances TRAIL-induced apoptosis. HeLa cancer cells were pretreated with artesunate $(60 \mu \mathrm{M})$ or vehicle $(0.1 \%$ DMSO) for $30 \mathrm{~min}$, and further incubated with TRAIL $(200 \mathrm{ng} / \mathrm{ml})$ for $12 \mathrm{~h}$. Whole cell lysates were analyzed by immunoblot for apoptotic proteins, caspase- 9 , caspase- 8 , caspase-7, caspase-3, Bid and PARP, using actin as loading control.

treatment of recombinant human TRAIL in the range of concentrations of $25-200 \mathrm{ng} / \mathrm{ml}$ on HeLa cancer cells showed only less than $16 \%$ cell death. These results implied that HeLa cancer cells were resistant to TRAIL-mediated cytotoxicity. However, pretreatment of artesunate in the concentration of $60 \mu \mathrm{M}$ for $30 \mathrm{~min}$ before $24-\mathrm{h}$ TRAIL treatment could increase the percentage of cell death significantly up to $30-60 \%$ depending on the concentration of TRAIL (Fig. 1B). Typical morphological changes of apoptotic cell death were observed under microscopy. Massive cell death was observed in HeLa cells at $24 \mathrm{~h}$ after treatment with a combination of $60 \mu \mathrm{M}$ artesunate and TRAIL $200 \mathrm{ng} / \mathrm{ml}$ as shown in Fig. 1C.

Sensitization of artesunate to TRAIL-induced apoptosis through the activation of caspase-mediated death signal. To confirm the activation of apoptotic signals by combined treatment with artesunate and TRAIL, we performed Western blot analysis of the cleavage of PARP, Bid and caspase- $8,-9,-3,-7$, which are hallmarks of cells undergoing apoptosis, in HeLa cells treated with artesunate and/or TRAIL (Fig. 2). The apoptosis -inducing effect of TRAIL was enhanced remarkably by artesunate pretreatment as shown in Fig. 2 by the increased cleavage of pro-caspase $-8,-9,-3,-7$, Bid and PARP. These results clearly showed that artesunate could sensitize HeLa cells in TRAILinduced apoptosis both the extrinsic apoptosis pathway (mitochondria independent pathway) and the intrinsic apoptosis 


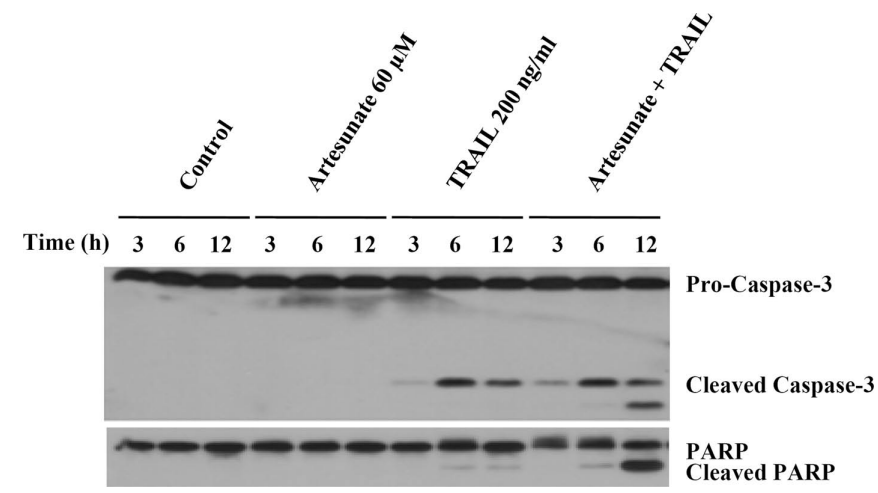

Figure 3. Kinetics of caspase-3 activation and PARP cleavage after single and combination treatment of TRAIL and artesunate. HeLa cancer cells were pretreated with artesunate $(60 \mu \mathrm{M})$ or vehicle $(0.1 \%$ DMSO) for $30 \mathrm{~min}$, and further incubated with TRAIL ( $200 \mathrm{ng} / \mathrm{ml})$ for 3,6 and $12 \mathrm{~h}$. Whole cell lysates were immunoblotted as described above with anti-caspase-3 and anti-PARP antibodies.

TRAIL $200 \mathrm{ng} / \mathrm{ml} \quad-\quad-\quad-\quad+\quad+\quad+$

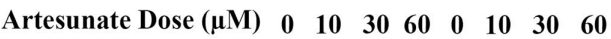

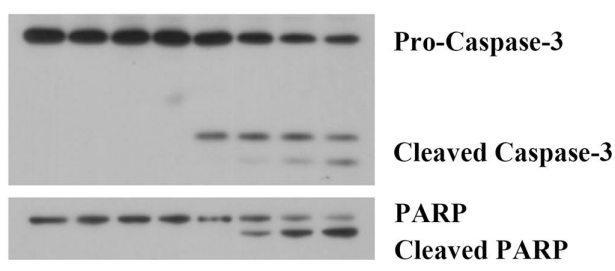

Figure 4. TRAIL-induced apoptosis enhanced by artesunate in a dosedependent manner. HeLa cancer cells were pretreated with artesunate $(10,30$ and $60 \mu \mathrm{M})$ or vehicle $(0.1 \%$ DMSO) for $30 \mathrm{~min}$, and further incubated with TRAIL $(200 \mathrm{ng} / \mathrm{ml})$ for $12 \mathrm{~h}$. Whole cell lysates were immunoblotted as described above with anti-caspase-3 and anti-PARP antibodies.

pathway (mitochondria dependent pathway). In addition, kinetics of caspase-3 activation and PARP cleavage after treatment with TRAIL, artesunate and their combination in the period time of 3-12 $\mathrm{h}$ were also investigated and the results were shown in Fig. 3. TRAIL-induced apoptosis occurred within $3 \mathrm{~h}$, showed the highest apoptosis at $6 \mathrm{~h}$ and then declined after $12 \mathrm{~h}$ of treatment. The combination treatment of TRAIL and artesunate could accelerate TRAIL-induced apoptosis continuously until $12 \mathrm{~h}$ of treatment by increasing the level of the activated caspase- 3 and the cleaved PARP remarkably. In addition, artesunate exhibited the synergist effect in inducing apoptosis selectively with TRAIL but not with TNF- $\alpha$ (data not shown). This synergist effect of artesunate in TRAIL-induced apoptosis was dose-dependent as shown in Fig. 4.

Effect of artesunate on other signaling pathway of TRAIL. Both apoptotic and non-apoptotic cell signaling could be influenced by NF-кB, PI3K/Akt and MAPK. Therefore, we further investigated effect of artesunate on other TRAILinduced signal pathway in HeLa cancer cells i.e., the NF- $\kappa B$, PI3K/Akt and the MAPK and pro-survival protein signaling pathways. After $12 \mathrm{~h}$ of treatment, TRAIL ( $200 \mathrm{ng} / \mathrm{ml})$ triggered survival signaling pathway, especially MAPKs, as revealed by increased phosphorylation of ERK, JNK and p38, whereas

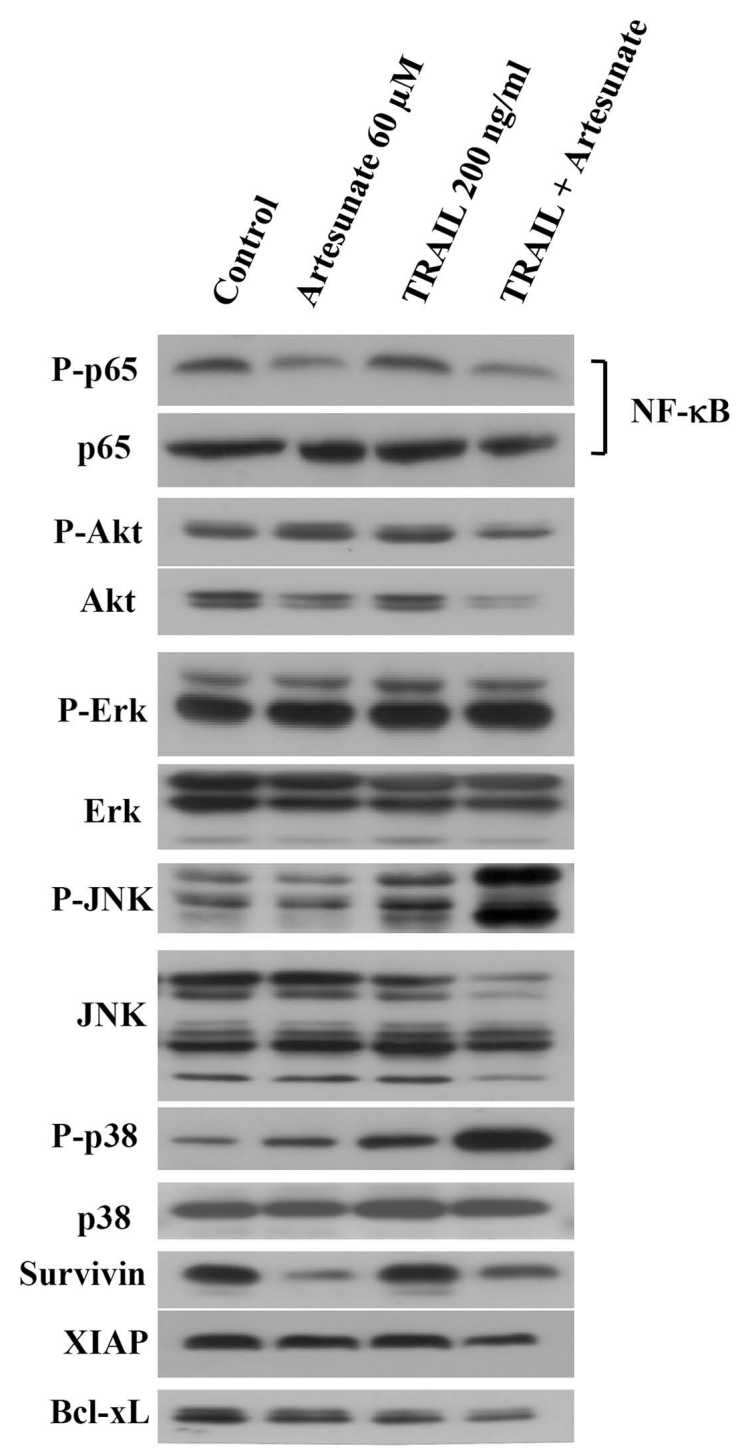

Figure 5. Effect of artesunate on signaling pathway of TRAIL. HeLa cells were pretreated with artesunate $(60 \mu \mathrm{M})$ for $30 \mathrm{~min}$, followed by incubation in the presence or absence of TRAIL ( $200 \mathrm{ng} / \mathrm{ml})$ for $12 \mathrm{~h}$. Whole cell lysates were then analyzed by immunoblot for levels of total and phosphorylated forms of Akt, Erk, JNK, p38, NF-kB p65 and the total forms of survival protein; Bcl-xL, $\mathrm{XIAP}$ and survivin.

only a little effect or no effect by TRAIL on NF-kB p65 and Akt pathway, which was already constitutively activated in common HeLa cancer cells (Fig. 5). After the combined treatment of TRAIL and artesunate, the phosphorylation of MAPKs, i.e., ERK, JNK and $\mathrm{p} 38$, was induced significantly and TRAILinduced NF- $\mathrm{kB}$ and Akt activation was significantly suppressed by artesunate. The signal of pro-survival proteins, survivin, XIAP, Bcl-xL, were also determined and the results clearly showed down-regulation of these pro-survival proteins signals depending on the concentration of artesuante as shown in the Fig. 6. In addition, the decrease of these pro-survival proteins after the combined treatment of TRAIL and artesunate was observed markedly at $12 \mathrm{~h}$ of treatment.

Artesunate inhibits TRAIL-induced NF- $\kappa B$ activation. As the $\mathrm{NF}-\mathrm{kB}$ is a major regulator of proinflammatory cytokine expression in TNF- $\alpha$ and TRAIL stimulation. We focused the 


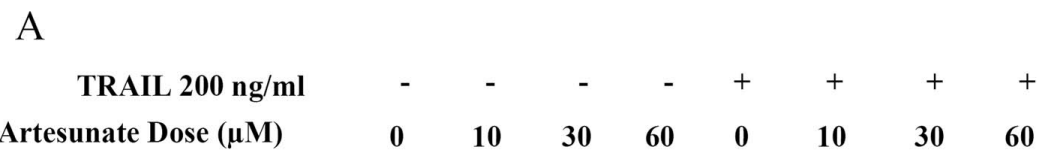

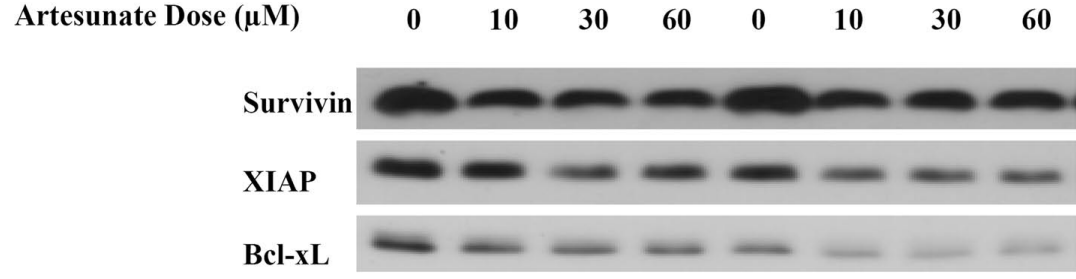

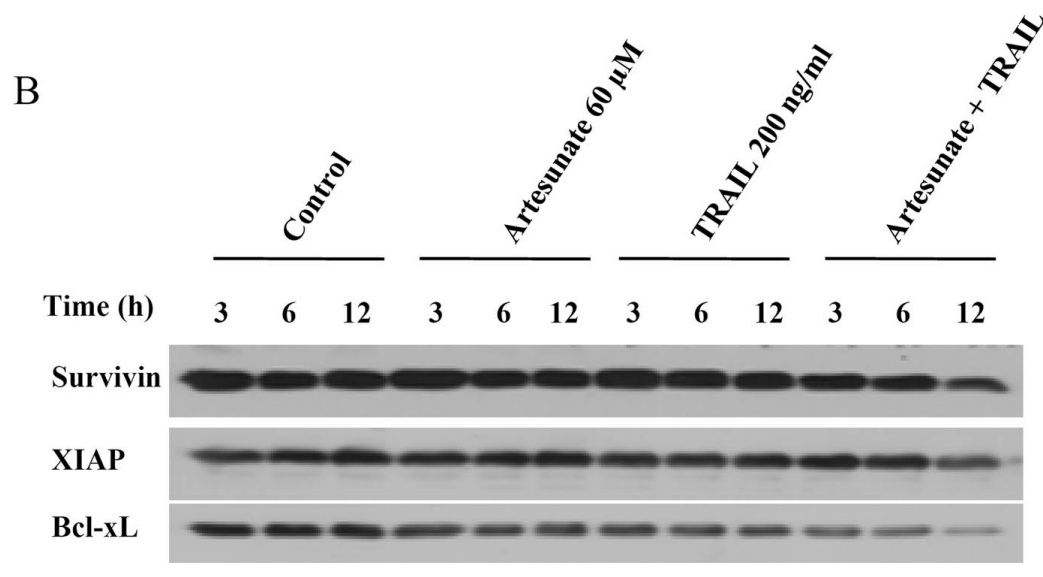

Figure 6. The inhibitory effect of artesunate on pro-survival proteins in a dose- (A) and (B) time-dependent manner. HeLa cancer cells were pretreated with artesunate $(10,30$ and $60 \mu \mathrm{M})$ or vehicle $(0.1 \%$ DMSO) for $30 \mathrm{~min}$, and further incubated with TRAIL (200 ng/ml) for 3-12 h. Whole cell lysates were immunoblotted as described above with anti-survivin, anti-XIAP and anti-Bcl-xL antibodies.

effect of artesunate on the $\mathrm{NF}-\kappa \mathrm{B}$-dependent pathway. To investigate this effect, the inhibitory effect of artesunate on TRAIL-induced $\mathrm{NF}-\kappa \mathrm{B}$ activation in luciferase expressing HeLa cancer cells, which containing NF- $\kappa \mathrm{B}$ transcription factor, was confirmed by using luciferase reporter assay. TNF- $\alpha$ was used as a potent inducer of NF- $\kappa \mathrm{B}$ activation. Treatment with $20 \mathrm{ng} / \mathrm{ml}$ TNF- $\alpha$ or $200 \mathrm{ng} / \mathrm{ml}$ TRAIL for $12 \mathrm{~h}$ induced activation and increased transcriptional activity of $\mathrm{NF}-\kappa \mathrm{B}$ by 7.1- and 2.05-fold, respectively, compared to control (Fig. 7A and $\mathrm{B}$ ). Artesunate pretreatment suppressed the TNF- $\alpha$-induced $\mathrm{NF}-\kappa \mathrm{B}$ transcriptional activity by approximately $33 \%$, and completely abolished the TRAIL-induced NF- $\kappa$ B transcriptional activity. These results clearly confirmed the inhibitory effect of artesunate on TRAIL-induced NF- $\kappa \mathrm{B}$ activation.

\section{Discussion}

Resistance to TRAIL can occur at different points in the signaling pathways of TRAIL-induced apoptosis. Overexpression of anti-apoptotic proteins and activation of different subunits of $\mathrm{NF}-\kappa \mathrm{B}$ is an important reason to affect on development of TRAIL resistance in certain types of cancer cells (18). In addition, there are numberous reports to suggest that activation of Akt could inhibit TRAIL-induced apoptosis in a wide variety of tumor cells (19-21). Activated Akt phosphorylates multiple proteins implicated in the control of cell survival (22). Our data clearly demonstrated that human cervical carcinoma cells exhibited resistance to TRAIL-induced apoptosis as shown by low cytotoxicity after TRAIL treatment for $24 \mathrm{~h}$ in Fig. 1B, possibly owing to high expression of activated NF- $\kappa$ B and Akt. Similarly, Bernard et al (23) reported high expression levels of c-Rel or activation of endogenous Rel/NF- $\kappa \mathrm{B}$ factors in HeLa cells. TRAIL was demonstrated to promote the survival and proliferation of primary human vascular endothelial cells by activating the Akt pathways (24), perhaps leading to developing TRAIL resistance of cancer cell by itself. The NF- $\mathrm{BB}$ and Akt activations clearly played important roles in failure to undergo apoptosis in response to TRAIL treatment. More recently, there is increasing evidence to support that artesunate may have a potential anti-cancer effect (25). In search for strategies to overcome TRAIL resistance of tumor cells, we tested the antitumor activity of artesunate on HeLa cancer cells. We provided evidence for the first time that artesunate was a potent sensitizer for TRAIL-induced apoptosis in HeLa cells. The mechanism of artesunate for TRAIL sensitization in HeLa cells was, at least in part, due to suppression of the NF- $\kappa \mathrm{B}$ and PI3K/Akt signal pathway by inhibition of phosphorylation of p65 and Akt. Correspondingly, artesunate significantly inhibited transcriptional activity of NF- $\kappa$ B induced by TRAIL and TNF- $\alpha$ as shown in Fig. 7. Some reports have shown that artesunate inhibited $N F-\kappa B$ activation induced by lipopolysaccharide (LPS), an inflammatory stimuli (26). Anti-apoptotic function of $\mathrm{NF}-\kappa \mathrm{B}$ activation in TRAIL signaling is mediated by the up-regulation of several anti-apoptotic genes such as cFLIP, Bcl-xL and XIAP (27). In addition, blocking PI3K/Akt has been reported to induce significant down-regulation of survivin and cytotoxicity in human multiple myeloma and liver carcinoma cells $(28,29)$. We further investigated the signal of pro-survival proteins, survivin, XIAP, Bcl-xL and the results clearly showed 
A

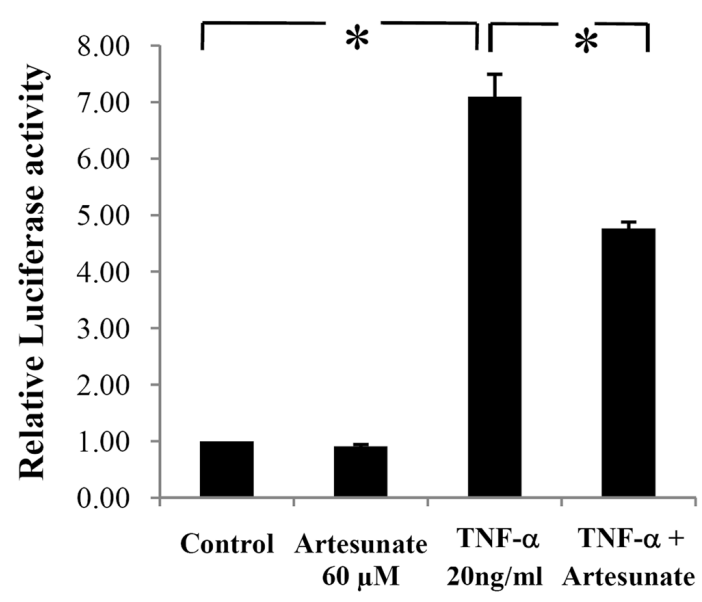

B

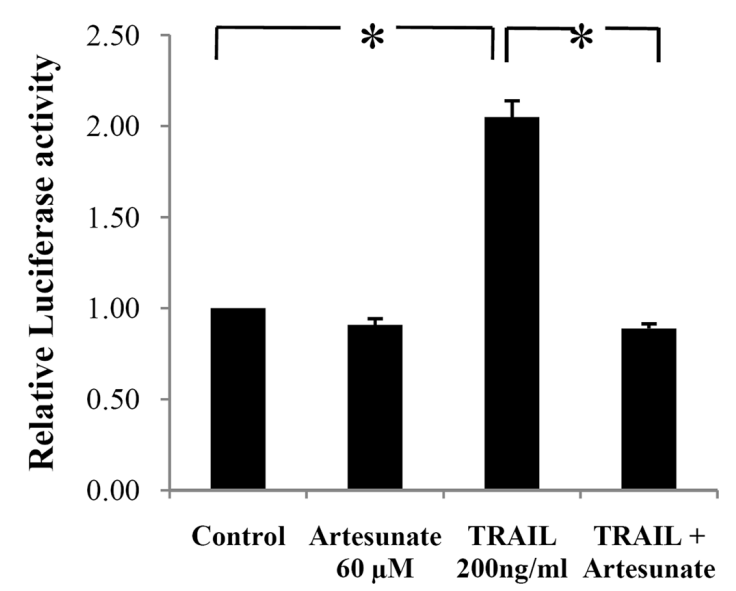

Figure 7. Effect of artesunate on TRAIL-induced NF- $\mathrm{BB}$ transcriptional activity. HeLa cells stably transfected with NF- $\mathrm{KB}$ luciferase reporter plasmid were pretreated with artesunate $(60 \mu \mathrm{M})$ for $30 \mathrm{~min}$, followed by incubation in the presence of TRAIL (200 ng/ml) (A) or TNF- $\alpha(20 \mathrm{ng} / \mathrm{ml})(B)$ for $12 \mathrm{~h}$. $\mathrm{NF}-\mathrm{\kappa B}$-mediated luciferase gene expression was then determined, normalized by total protein and then calculated as relative luciferase activity. Data are expressed as the mean \pm SD from three independent experiments.

down-regulation of these pro-survival proteins signals. These obviously decreased pro-survival proteins exhibited an important influence to augment and facilitate TRAIL-induced apoptosis in HeLa cancer cells leading to cancer cell death. These studies provided additional evidence regarding the role of survival protein mediated by the NF- $\mathrm{KB}$ and PI3K/Akt pathway, in the regulation of apoptosis. It has been reported that antiapoptotic factors, especially survivin, play a potential role in the resistance to activation-induced cell death and prognosis of neuroblastoma (22). Consistent with the report by Azuhata et al (30) in which higher levels of survivin correlated with greater resistance to TRAIL. Similar enhancement of TRAIL-induced apoptosis by down- regulation of survivin has been reported for resveratrol (31). Not only NF-kB or PI3K/Akt inhibition, but also down-regulation of pro-survival proteins by artesunate resulted in enhancement of TRAIL-induced apoptosis. We also found that this combined treatment of TRAIL and artesunate could induce phos-phorylation of p38, JNK, MAPK/ERK, which are implicated in propagating the apoptotic signal. The sensitization of artesunate in TRAIL-induced apoptosis clearly involved both the extrinsic (mitochondriaindependent pathway) and the intrinsic apoptosis pathway (mitochondria-dependent pathway). Artesunate enhanced the cleavage of caspase- 8 induced by TRAIL. Activated caspase- 8 triggers apoptosis, either directly activating downstream executioner caspase such as caspase-3, and caspase-7, or by cleaving Bid that activates the mitochondrial pathway to cell death. Bid is cleaved by caspase- 8 to a truncated version of the molecule tBid, which translocates from cytosol to mitochondria and induces the release of cytochrome $\mathrm{C}$ and finally activates caspase-9. Activated caspase-9 then activates downstream executioner caspases such as caspase-3, which subsequently cleave many important intracellular proteins such as PARP and DNA fragmentation factor, resulting in morphological changes in apoptosis and cell death. It was possible that artesunate induced the cleavage of Bid and the activation of caspase-9 in Bcl-xL-sensitive manner as shown by the increase of the degradation of caspase- 9 and Bid together with the decrease of Bcl-xL, anti-apoptotic protein. Artesunate also inhibited the XIAP protein, which was up-regulated by NF- $\mathrm{KB}$ facilitating the process of activation of caspase- 3 and-7 by the activated caspase-9. Among the IAP family proteins, XIAP exhibits the strongest anti-apoptotic properties and inhibits apoptosis signaling by binding to active caspase- 3 and -7 and by preventing caspase-9 activation (32). It has been reported that inhibition of the apoptosis pathway involves up-regulation of apoptotic protein inhibitors, IAP, which leads to attenuation of the death receptor-mediated signal pathway (33). The obvious enhancement of the caspase- 3 activation and the cleavage of PARP by synergist effect of artesunate on TRAIL-induced apoptosis were dose- and time-dependent.

In conclusion, we demonstrated the first evidence that artesunate effectively enhances TRAIL-mediated cytotoxicity by suppressing the activation of NF- $\mathrm{kB}$ and Akt, resulting in the decrease of pro-survival proteins, leading to trigger both extrinsic and intrinsic apoptosis. This suggests that the combination treatment of TRAIL and artesunate may be an effective strategy for cancer therapy in the near future.

\section{Acknowledgements}

This study was supported in part by a Japanese-Thai Collaborative Scientific Research Fellowship (JSPS-NRCT).

\section{References}

1. Wang S: The promise of cancer therapeutics targeting the TNFrelated apoptosis-inducing ligand and TRAIL receptor pathway. Oncogene 27: 6207-6215, 2008.

2. Perez-Cruz I, C'arcamo JM and Golde DW: Caspase-8 dependent trail-induced apoptosis in cancer cell lines is inhibited by vitamin $\mathrm{C}$ and catalase. Apoptosis 12: 225-234, 2007.

3. Ashkenazi A, Pai RC, Fong S, et al: Safety and antitumor activity of recombinant soluble Apo2 ligand. J Clin Invest 104: 155-162, 1999.

4. Schaefer U, Voloshanenko O, Willen D and Walczak H: TRAIL: a multifunctional cytokine. Front Biosci 12: 3813-3824, 2007. 
5. Rushworth SA and Micheau O: Molecular crosstalk between TRAIL and natural antioxidants in the treatment of cancer. Br J Pharmacol 157: 1186-1188, 2009.

6. Falschlehner C, Emmerich CH, Gerlach B and Walczak H: TRAIL signaling: decisions between life and death. Int J Biochem Cell Biol 39: 1462-1475, 2007.

7. Merino D, Lalaoui N, Morizot A, Solary E and Micheau O TRAIL in cancer therapy: present and future challenges. Expert Opin Ther Targets 11: 1299-1314, 2007.

8. Kannappan R, Ravindran J, Prasad S, Sung B, Yadav VR, Reuter S, Chaturvedi MM and Aggarwa BB: $\gamma$-Tocotrienol promotes TRAILinduced apoptosis through reactive oxygen species/extracellular signal-regulated kinase/p53-mediated upregulation of death receptors. Mol Cancer Ther 9: 2196-2207, 2010.

9. Meurette O, Fontaine A, Rebillard A, Le Moigne G, Lamy T and Lagadic-Gossmann D: Cytotoxicity of TRAIL/anticancer drug combinations in human normal cells. Ann N Y Acad Sci 1090: 209-216, 2006.

10. Meshnick SR, Taylor TE and Kamchonwongpaisan S: Artemisinin and the antimalarial endoperoxides: from herbal remedy to targeted chemotherapy. Microbiol Rev 60: 301-315, 1996.

11. Haynes RK: Artemisinin and derivatives: the future for malaria treatment? Curr Opin Infect Dis 14: 719-726, 2001.

12. Berger TG, Dieckmann D, Efferth T, Schultz ES, Funk JO, Baur A and Schuler G: Artesunate in treatment of metastatic uveal melanoma - first experiences. Oncol Rep 14: 1599-1603, 2005.

13. Efferth T, Sauerbrey A, Olbrich A, Gebhart E, Rauch P, Weber HO, Hengstler JG, Halatsch ME, Volm M, Tew KD, Ross DD and Funk JO: Molecular modes of action of artesunate in tumor cell lines. Mol Pharmacol 64: 382-394, 2003.

14. Efferth T, Briehl M and Tome ME: Role of antioxidant genes for the activity of artesunate against tumor cells. Int $\mathrm{J}$ Oncol 23 : $1231-1235,2003$

15. Dell'Eva R, Pfeffer U, Ven'e R, Anfosso L, Forlani A, Albini A and Efferth T: Inhibition of angiogenesis in vivo and growth of Kaposi's sarcoma xenograft tumors by the anti-malarial artesunate. Biochem Pharmacol 68: 2359-2366, 2004.

16. Lirdprapamongkol K, Sakurai H, Kawasaki N, Choo MK Saitoh Y, Aozuka Y, Singhirunnusorn P, Ruchirawat S, Svasti J and Saiki I: Vanillin suppresses in vitro invasion and in vivo metastasis of mouse breast cancer cells. Eur J Pharm Sci 25 57-65, 2005.

17. Choo MK, Kawasaki N, Singhirunnusorn P, Koizumi K, Sato S, Akira S, Saiki I and Sakurai H: Blockade of transforming growth factor-beta-activated kinase 1 activity enhances TRAIL-induced apoptosis through activation of a caspase cascade. Mol Cancer Ther 5: 2970-2976, 2006.

18. Zhang L and Fang B: Mechanisms of resistance to TRAILinduced apoptosis in cancer. Cancer Gene Ther 12: 228-237, 2005.

19. Asakuma J, Sumitomo M, Asano T and Hayakawa M: Selective Akt inactivation and tumor necrosis factor-related apoptosisinducing ligand sensitization of renal cancer cells by low concentrations of paclitaxel. Cancer Res 63: 1365-1370, 2003.
20. Bild AH, Mendoza FJ, Gibson EM, Huang M, Villanueva J, Garrington TP, Jove R, Johnson GL and Gibson SB: MEKK1induced apoptosis requires TRAIL death receptor activation and is inhibited by AKT/PKB through inhibition of MEKK1 cleavage. Oncogene 21: 6649-6656, 2002.

21. Chen X, Thakkar H, Tyan F, Gim S, Robinson H, Lee C, Pandey SK, Nwokorie C, Onwudiwe N and Srivastava RK: Constitutively active Akt is an important regulator of TRAIL sensitivity in prostate cancer. Oncogene 20: 6073-6083, 2001.

22. Kim S, Kang J, Qiao J, Thomas RP, Evers BM and Chung DH: Phosphatidylinositol 3-kinase inhibition down-regulates survivin and facilitates TRAIL-mediated apoptosis in neuroblastomas. J Pediatr Surg 39: 516-521, 2004.

23. Bernard D, Quatannens B, Vandenbunder B and Abbadie C: Rel/ NF-kappaB transcription factors protect against tumor necrosis factor (TNF)-related apoptosisinducing ligand (TRAIL)-induced apoptosis by up-regulating the TRAIL decoy receptor DcR1. J Biol Chem 276: 27322-27328, 2001.

24. Secchiero P, Gonelli A, Carnevale E, Milani D, Pandolfi A, Zella D and Zauli G: TRAIL promotes the survival and proliferation of primary human vascular endothelial cells by activating the Akt and ERK pathways. Circulation 107: 2250-2256, 2003.

25. Ferreira JF, Luthria DL, Sasaki T and Heyerick A: Flavonoids from Artemisia annua L. as antioxidants and their potential synergism with artemisinin against malaria and cancer. Molecules 15: 3135-3170, 2010.

26. Li B, Zhang R, Li J, Zhang L, Ding G, Luo P, He S, Dong Y, Jiang W, Lu Y, Cao H, Zheng J and Zhou H: Antimalarial artesunate protects sepsis model mice against heat-killed Escherichia coli challenge by decreasing TLR4, TLR9 mRNA expressions and transcription factor NF-kappa B activation. Int Immunopharmacol 8: 379-389, 2008.

27. Falschlehner C, Emmerich $\mathrm{CH}$, Gerlach B and Walczak H: TRAIL signaling: decisions between life and death. Int J Biochem Cell Biol 39: 1462-1475, 2007.

28. Hideshima T, Catley L, Raje N, et al: Inhibition of Akt induces significant downregulation of survivin and cytotoxicity in human multiple myeloma cells. Br J Haematol 138: 783-791, 2007.

29. Tang C, Lu YH, Xie JH, Wang F, Zou JN, Yang JS, Xing YY and $\mathrm{Xi}$ T: Downregulation of survivin and activation of caspase-3 through the PI3K/Akt pathway in ursolic acid-induced HepG2 cell apoptosis. Anticancer Drugs 20: 249-258, 2009.

30. Azuhata T, Scott D and Takamizawa S: The inhibitor of apoptosis protein survivin is associated with high-risk behavior of neuroblastoma. J Pediatr Surg 36: 1785-1791, 2001.

31. Fulda $S$ and Debatin KM: Sensitization for tumor necrosis factor-related apoptosis-inducing ligand-induced apoptosis by the chemopreventive agent resveratrol. Cancer Res 64: 337-346, 2004.

32. Eckelman BP, Salvesen GS and Scott FL: Human inhibitor of apoptosis proteins: why XIAP is the black sheep of the family. EMBO Rep 7: 988-994, 2006.

33. Suzuki A and Shiraki K: Tumor cell 'dead or alive': caspase and surviving regulate cell death, cell cycle and cell survival. Histol Histopathol 16: 583-593, 2001. 